\title{
Using affinity analysis in diagnosing the needs of patients as regards e-Health
}

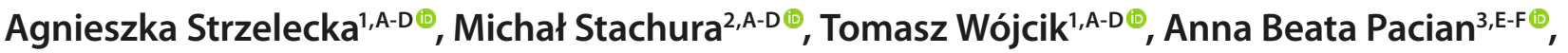 \\ Teresa Kulikk ${ }^{3, F}$, Jolanta Pacian ${ }^{3, B}{ }^{\oplus}$, Monika Kaczoruk ${ }^{3,4, B}{ }^{\circ}$, Elżbieta Monika Galińska ${ }^{4, B} \oplus$, \\ Ewa Kawiak-Jawor ${ }^{3, \mathrm{~B}-\mathrm{C} \oplus}$, Grażyna Nowak-Starz ${ }^{1, \mathrm{~A}, \mathrm{E}-\mathrm{F} \oplus}$ \\ ${ }^{1}$ Collegium Medicum Institute of Health Sciences, Kochanowski University, Kielce, Poland \\ ${ }^{2}$ Department of Economics and Finance, Faculty of Law and Social Sciences, Jan Kochanowski University, Kielce, Poland \\ ${ }^{3}$ Department of Public Health, Medical University, Lublin, Poland \\ ${ }^{4}$ Institute of Rural Heath, Lublin, Poland \\ A - Research concept and design, B - Collection and/or assembly of data, C - Data analysis and interpretation, \\ $D$ - Writing the article, $E$ - Critical revision of the article, $F$ - Final approval of article
}

Strzelecka A, Stachura M, Wójcik T, Pacian AB, Kulik T, Pacian J, Kaczoruk M, Galińska EM, Kawiak-Jawor E, Nowak-Starz G. Using affinity analysis in diagnosing the needs of patients as regards e-Health. Ann Agric Environ Med. 2020; 27(3): 435-441. doi: 10.26444/aaem/123872

\begin{abstract}
Introduction. E-Health tools allow a medical facility to set a given patient's data in order using ICT techniques, and the patient to use those techniques when contacting a given organisation.

Materials and method. Secondary statistical data was used in the research. The study was carried out among primary health care patients. Mining for affinity rules was done in the R programme. The apriori and inspect functions from the arules package were used. Moreover, any redundant rules were removed from thoseobtained using the afero-mentioned method. Applying the general description of the affinity analysis method onto the survey described herein, it should be stressed that the aim of using affinity analysis was to discover the rules which contain the sub-transaction $B=\left\{\mathrm{V} \_6=1\right\}$ as a consequent. This was determined by the intention to discover associations regarding the knowledge about a uniform information system that the patients under study might have.

Results. In the discovered rules, the antecedent most often contained an indication of the need for introducing a uniform solution as regards telemedicine. Moreover, according to the opinions of ,conscious'patients, a uniform IT system should improve the work at primary health care institutions, introducing an on-line booking system for visits should improve the productivity and comfort of doctors, and an IT system should provide unambiguous identification of a patient.

Conclusions. There is potential in using affinity analysis within e-Health. The example of affinity analysis described in his study led to the discovery of interesting and important (from the point of view of a medical facility) regularities regarding the knowledge and expectations of patients as regards e-Health.
\end{abstract}

\section{Key words}

patient, primary health care, e-health, affinity analysis

\section{INTRODUCTION}

As a result of profound technical development, the idea of telemedicine was broadened and along with other general changes is currently referred to as e-Health $[1,2]$. Among the many definitions of e-Health, it is described as "a field which emerged from the cooperation of medical information technology, public health and business related to health care and access to information over the Internet and other means of communication" $[3,4]$. According to the World Health Organization, e-Health is "an effective, economical and safe utilization of information and communication technology to facilitate any actions related to health care, which include providing health care services, systems for observing the fields connected with health, health education, the development of professional literature and knowledge, and scientific research" $[5,6]$. The European Commission gives its definition of e-Health as "using modern information and communication technology to meet the needs of citizens, patients, specialists in health care, and health care service

Address for correspondence: Monika Kaczoruk, Department of Public Health, Medical University, Lublin, Poland

E-mail: monika.kaczoruk@gmail.com

Received: 23.12.2019; accepted: 09.06.2020; first published: 25.06.2020 providers, as well as politicians" [7]. E-Health is the use of information and communication technology to reinforce health care. It is related to the forms of prevention and education, diagnosis, therapy and care provided using digital technology, regardless of time and place [8].

E-Health tools allow the medical facility to set a given patient's data in order using ICT techniques, and the patient to use those techniques when contacting a given organisation [9]. It should be noted that if a medical institution is a provider of service for the patients, then it can be treated as a service provider in the sense of an economic market and its patients as the clients. What is more, given the above, the total of medical services can be treated as a set of items. Looking from this perspective, certain tools can be adapted which have been used for years in marketing and other fields of study. Among those tools, affinity analysis within the approach of data mining warrants special attention. Affinity analysis can be used not only in regard to the present functioning of a given medical institution, but also to diagnose the needs and expectations of the patients in terms of using e-Health in order fort the institution take suitable action (e.g. expanding and updating the offers directed at the patient) $[10,11]$. The success of a medical institution is determined by the needs of the patients - the offers and services are directed at the needs 
and expectations of the patients. Relationship marketing, the main rule of which is not to lose a patient once acquired, may play a significant role in this process [12].

In general, affinity analysis performed on a data set is used, among others, to find certain interesting regularities, relationships, or correlations (called affinities in this context) - in particular the hidden ones which are not immediately noticeable $[13,14]$. In the case of large databases, which by their very nature lead to large numbers of possible/potential associations, specific algorithms are used which lead to quick and effective discovery of association rules $[15,13]$. The origin of the problem of discovering association rules goes back to the so-called Market Basket Analysis (MBA) problem, the aim of which was to determine the natural patterns of choices made by consumers-clients in supermarkets. These patterns are given as the most frequently bought sets (baskets) of products [15].

The description of the essence of affinity analysis, however, is put into the context of the afore-mentioned survey studies.

\section{OBJECTIVES}

The aim of the study is to use affinity analysis to diagnose the needs of (aware) patients of primary health care, who were made aware of the knowledge and expectations regarding e-Health.

Using affinity analysis in relation to e-Health is - in the authors'subjective opinion - innovative. The affinity analysis described herein is used in many fields of research, whereas the authors have found the lack of use of this tool in the field of e-Health. In the authors'opinion, the analysis used has great potential, both in learning andinf practical use, in the field described herein.

\section{MATERIALS AND METHOD}

Secondary statistical data was used in the research. The primary study, with a positive opinion No. 29/2011), received on 18 March 2011 from the Bioethics Commission of the Faculty of Health Sciences of the Jan Kochanowski University in Kielce, was carried out within the period June - December 2011. At that time, the method of two-stage group sampling with stratification according to the type of institution was used. During the first stage, based on data from the National Health Fund and the National Register of Health Care Facilities (as of May 2011) a list was compiled of 301 medical institutions which had a contract signed with the National Health Fund as regards GP services, and which were in the area of the Swietokrzyskie Province. Next, a division was made into public and non-public health care centres which provided primary car; of these there were 147 and 154, respectively. During the next stage, 20 institutions were chosen at random - 10 public and 10 non-public. After that, the numbers of patients to include in the study in each of those centres in proportion to the total of a centre's patients were determined.

Once all the directors of the chosen institutions have given their consent, 422 questionnaires were qualified for the final analysis - 216 from public and 206 from non-public primary care institutions. A questionnaire of own design had 29 closed questions regarding the type of the institution under study, the demographic, social and economic situation, the patient's self-assessment in terms of computer skills, awareness of e-Health services, the level of knowledge about e-Health, and the benefits of patients that result from introducing IT systems in primary care institutions.

The research was conducted on a representative sample of patients of public and non-public health care centres from the Swietokrzyskie Province. The research was conducted in 20 public and non-public institutions of primary health care in the same province. In total, 422 patients were examined - 259 women $(61.37 \%)$ and 163 men (38.63\%). Patients' age: 45-64 years old $(136 ; 32.23 \%), 30-44$ years old $(104 ; 24.64 \%), 20-29$ years old $(102 ; 24.17 \%), 65$-years-old and above $(57 ; 13.51 \%)$, and $18-19$ years old $(23 ; 5.45 \%)$. The knowledge level of the respondents was evaluated on the basis of the questionnaire prepared by the author (which was subject to the validation process). The character and contents of the questions were based on the guidelines contained in the Act of 28 April 2011 on the Information System in Health Care, the document Informatization Directions "e-Zdrowie Polska" for the years 2011-2015, and the guidelines of the Centre for Information Systems in Health Care.

The variables used for the analysis performed in this study are presented in Table 1.

Let us consider then a set $m$ of variables $V_{1}, V_{2}, \ldots, V_{\mathrm{m}}$, each of which represents a single question from the survey and can assume exactly one of its variants, corresponding to a single choice in the list of answers to a given question. Let the variants of variable be denominated as: $v_{i,}, v_{i}, \ldots, v_{i k_{i}}$, where $k_{i}$ is the number of variants of variable. In the survey below, the numbers $k_{i}$ assume the values from 2 to 5 .

With these notations, a transaction is any set $A^{\prime}$ in the form $A^{\prime}=\left\{V_{1}=v_{1 j_{2}}, V_{2}=v_{2 j_{2}}, \ldots, V_{\mathrm{m}}=v_{m j_{m}}\right\}$, which is made up of a certain collection of variants assigned to all $m$ variables. In turn, a sub-transaction of transaction $A^{\prime}$ is any non-empty subset $A \subseteq A^{\prime}$. Furthermore, let $V(A)$ be a set of variables which are found in sub-transaction $A$.

Among the total of transactions which are a natural means of representing all the potential choices that patients can make, the particularly interesting transactions are those which appear as sets of single answers in the survey. It is those sets that are the basis for discovering the association rules. The set of all such transactions is denoted as $T$. Let its size be equal to $N$.

An association rule is the ordered pair $(A, B)$ of subtransactions, conventionally denoted as: $A \Rightarrow B$, with the property that these sub-transactions do not contain mutual variables, meaning $V(A) \cap V(B)=\varnothing$. In particular then, these sub-transactions are disjoint/exclusive, so $A \cap B=\varnothing$. Part $A$ of rule $A \Rightarrow B$ is called the antecedent, and part $B$ - the consequent, and the number of all variables that are in the rule - the rule's length [15].

Let us note that the sum $A \cup B$ of sub-transaction $A$ and $B$ is also a sub-transaction. This means it is part of a certain number of transactions which represent sets of choices made by the patients participating in the survey. Let us denote this number of transactions as $n(A \cup B)$. The transactions themselves, then, are called transactions supporting subtransaction $A \cup B$, or supporting rule $A \Rightarrow B$. Similarly, let $n(A)$ and $n(B)$ be the numbers of transactions supporting sub-transactions $A$ and $B$, respectively.

To evaluate the quality/properness of a discovered association rule $A \Rightarrow B$, the following measures can be used [13]: 
Table 1. Analysed variables together with their variants

\begin{tabular}{|c|c|c|}
\hline Code & Name of variable with full description & Variants \\
\hline V1 & Ability to use a computer & $\begin{array}{c}1=\text { "none" } \\
2=\text { "poor" } \\
3=\text { "satisfactory" } \\
4=\text { "good" } \\
5=\text { "very_good" }\end{array}$ \\
\hline V2 & Access to a computer at home & $\begin{array}{l}0=\text { "no" } \\
1=\text { "yes" }\end{array}$ \\
\hline V3 & Access to the Internet at home & $\begin{array}{l}0=\text { "no" } \\
1=\text { "yes" }\end{array}$ \\
\hline V4 & Booking an appointment with GPs via the Internet & $\begin{array}{c}0=\text { "no" } \\
1=\text { "yes" } \\
2=\text { "I do not know" }\end{array}$ \\
\hline V5 & The unit has a website & $\begin{array}{c}0=\text { "no" } \\
1=\text { "yes" } \\
2=\text { "I do not know" }\end{array}$ \\
\hline V6 & $\begin{array}{l}\text { The need for introducing a unified IT system in } \\
\text { health care }\end{array}$ & $\begin{array}{c}0=\text { "no" } \\
1=\text { "yes" } \\
2=\text { "I do not know" }\end{array}$ \\
\hline V7 & Patient's knowledge about e-Health strategy & $\begin{array}{l}0=\text { "no" } \\
1=\text { "yes" }\end{array}$ \\
\hline V8 & $\begin{array}{l}\text { The need for introducing a unified IT solution in } \\
\text { telemedicine }\end{array}$ & $\begin{array}{c}0=\text { "no" } \\
1=\text { "yes" } \\
2=\text { "no opinion" }\end{array}$ \\
\hline V9 & $\begin{array}{l}\text { The IT system should provide (deliver) precise } \\
\text { patient's identification }\end{array}$ & $\begin{array}{c}0=\text { "no" } \\
1=\text { "yes" } \\
2=\text { "no opinion" }\end{array}$ \\
\hline V10 & $\begin{array}{l}\text { The IT system will facilitate work of family doctors } \\
\text { (GPs) }\end{array}$ & $\begin{array}{c}0=\text { "no" } \\
1=\text { "yes" } \\
2=\text { "no opinion" }\end{array}$ \\
\hline V11 & $\begin{array}{l}\text { Introducing an e-Prescription system will } \\
\text { contribute to monitoring medicaments bought by } \\
\text { the patients }\end{array}$ & $\begin{array}{c}0=\text { "no" } \\
1=\text { "yes" } \\
2=\text { "no opinion" }\end{array}$ \\
\hline V12 & e-Reservation will improve doctors' effectiveness & $\begin{array}{c}0=\text { "no" } \\
1=\text { "yes" } \\
2=\text { "no opinion" }\end{array}$ \\
\hline V13 & $\begin{array}{l}\text { Implementing e-Services will allow improvement of } \\
\text { the qualifications of medical staff }\end{array}$ & $\begin{array}{c}0=\text { "no" } \\
1=\text { "yes" } \\
2=\text { "no opinion" }\end{array}$ \\
\hline V14 & $\begin{array}{l}\text { Booking appointments via the Internet will allow } \\
\text { choosing a date suitable for the patient }\end{array}$ & $\begin{array}{l}0=\text { "no" } \\
1=\text { "yes" }\end{array}$ \\
\hline V15 & $\begin{array}{l}\text { e-Reservation will allow a patient to see the doctor } \\
\text { without unnecessary waiting outside the (GP's) } \\
\text { office }\end{array}$ & $\begin{array}{l}0=" \text { no" } \\
1=\text { "yes" }\end{array}$ \\
\hline V16 & $\begin{array}{l}\text { e-Medical Documentation will allow a decrease } \\
\text { in the number of mistakes connected with } \\
\text { medicament's interaction }\end{array}$ & $\begin{array}{l}0=" \text { no" } \\
1=\text { "yes" }\end{array}$ \\
\hline V17 & $\begin{array}{l}\text { e-Medical Documentation will allow a decrease in } \\
\text { the number of wrongly issued prescriptions }\end{array}$ & $\begin{array}{l}0=\text { "no" } \\
1=\text { "yes" }\end{array}$ \\
\hline V18 & $\begin{array}{l}\text { e-Medical Documentation will allow doctors to } \\
\text { save time }\end{array}$ & $\begin{array}{l}0=\text { "no" } \\
1=\text { "yes" }\end{array}$ \\
\hline V19 & Possibility of receiving tests' results via e-mail & $\begin{array}{c}0=\text { "no" } \\
1=\text { "yes" } \\
2=\text { "sporadically" } \\
3=\text { "I am unaware } \\
\text { of such possibility" }\end{array}$ \\
\hline
\end{tabular}

\section{- support}

$\operatorname{supp}(A \Rightarrow B)=\frac{n(A \cup B)}{N}$

This is the percentage of transactions among the total $N$ of transactions in the database that support the rule $A \Rightarrow B$. It can be said that the higher the support, the more frequently a rule occurs. The following is always true: $0 \leq \operatorname{conf}(A \Rightarrow B) \leq 1$.

\section{- confidence}

$\operatorname{conf}(A \Rightarrow B)=\frac{\operatorname{supp}(A \cup B)}{\operatorname{supp}(A)}=\frac{n(A \cup B)}{n(A)}$

This is the percentage of transactions which support the rule $A \Rightarrow B$ among those transactions which support the sub-transaction $A$. Confidence can be interpreted as the conditional probability of the occurrence of $B$, once it is known that $A$ occurred. Thus, confidence shows the strength of an association rule. The following is always true: $0 \leq \operatorname{conf}(A \Rightarrow B) \leq 1$.

$$
\begin{aligned}
& \text { - lift } \\
& \operatorname{lift}(A \Rightarrow B)=\frac{\operatorname{conf}(\mathrm{A} \Rightarrow \mathrm{B})}{\operatorname{supp}(\mathrm{B})}=\frac{\operatorname{supp}(\mathrm{A} \cup \mathrm{B})}{\operatorname{supp}(\mathrm{A}) \cdot \operatorname{supp}(\mathrm{B})}=\frac{N \cdot n(A \cup B)}{n(A) \cdot n(B)}
\end{aligned}
$$

This is the ratio of a rule's confidence to the support of the consequent of that rule. The following is always true: $\operatorname{lift}(A \Rightarrow B) \geq 0$. Lift can be interpreted as the deviation of the support of the analysed rule $A \Rightarrow B$ from the support which that rule would have had, had the transactions supporting the sub-transactions $A$ and $B$ occurred independently in the database. If lift equals 1 , it is assumed that the occurrences of the antecedent and the consequent do not influence each other. If lift is greater than 1 , it means that the transactions supporting both the antecedent and the consequent have a tendency to occur relatively frequently. And in turn, if the lift is lower than 1, then the transactions supporting both the antecedent and the consequent have a tendency to rarely occur. Thus, the greater the lift, the stronger the rule is.

Mining for affinity rules was done in the R programme. The apriori and inspect functions from the arules package were used [16]. Moreover, any redundant rules were removed from the ones obtained using the aforementioned method. Namely, if there were two rules among the ones discovered $A_{1} \Rightarrow B$ and $A_{2} \Rightarrow B$, where $A_{1} \subseteq A_{2}$, then rule $A_{2} \Rightarrow B$ was removed.

\section{RESULTS}

The obtained association rules were visualised using the tools from the arulesViz package [16]. The points in the Figure represent the association rules, and their placement corresponds to the value of support and confidence, whereas the colour dye represents the value of lift (Fig. 1).

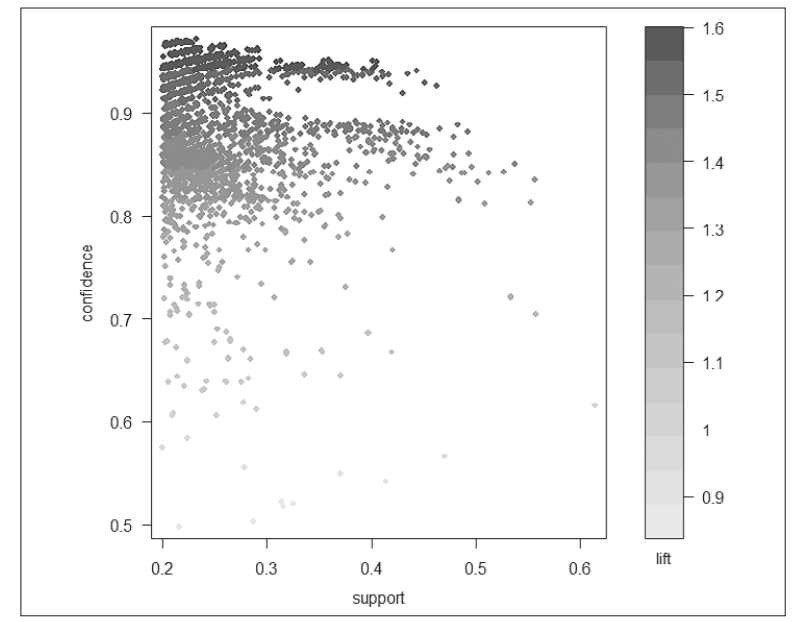

Figure 1. Values of lift in relation to the levels of support and confidence 
From the questionnaire's point of view, the interesting rules are those that have support and confidence equal to at least the predetermined minimal thresholds (for this study, a support $\geq 0.4$ and confidence $\geq 0,9$ were assumed), and at the same time they have the highest lift (which is why further on the rules are given after having sorted them from the highest to the lowest lift).

The assumed minimal threshold values for support and confidence were selected arbitrarily; however, the choice was made after initial study where the influence of many different threshold levels on the number of obtained rules was verified (these were the following for support: $0.30 ; 0.32 ; 0.34 ; 0.36$; $\ldots ; 0.60$, and for confidence: $0.40 ; 0.42 ; 0.44 ; \ldots ; 0.90)$. A rule was assumed, although, that the final selected thresholds should be as high as possible and produce not more than 20 significant rules at the same time. The chosen thresholds seem to be consistent (coherent) with the placement of points in Figure 1, as it outlines the rules grouped at the "cape" protruding from the other mass of points.

Applying the general description of the affinity analysis method onto the survey described herein, one should stress that the aim of using affinity analysis was to discover the rules which contain the sub-transaction $B=\left\{V_{6}=1\right\}$ as a consequent. This was determined by the intention to discover associations regarding the knowledge about a uniform information system that the patients under study might have.

On the other hand, the form of a rule's antecedent was determined only by the fact that it had to have variables other than $V_{6}$, and the fact that there could be from one to four of them. This was done to limit the number of "determinants" of variable $V_{6}$. In other words, a maximum length of 5 was set for the rules. The discovered rules with consequent $B=\left\{V_{6}=1\right\}$ are presented in Table 2.

Table 2. The discovered strong association rules concerning the case of the patients'knowledge of a uniform information system

\begin{tabular}{clcccc}
\hline No. & antecedent $A$ & consequent $B$ & support & confidence & lift \\
\hline 1 & $\{\mathrm{~V} 8=1, \mathrm{~V} 10=1, \mathrm{~V} 12=1\}$ & $\{\mathrm{V} 6=1\}$ & 0.405213 & 0.95 & 1.541923 \\
\hline 2 & $\{\mathrm{~V} 8=1, \mathrm{~V} 9=1, \mathrm{~V} 11=1\}$ & $\{\mathrm{V} 6=1\}$ & 0.405213 & 0.944751 & 1.533404 \\
\hline 3 & $\{\mathrm{~V} 8=1, \mathrm{~V} 10=1, \mathrm{~V} 11=1\}$ & $\{\mathrm{V} 6=1\}$ & 0.400474 & 0.944134 & 1.532402 \\
\hline 4 & $\{\mathrm{~V} 8=1, \mathrm{~V} 11=1\}$ & $\{\mathrm{V} 6=1\}$ & 0.412322 & 0.940541 & 1.52657 \\
\hline 5 & $\{\mathrm{~V} 8=1, \mathrm{~V} 9=1, \mathrm{~V} 12=1\}$ & $\{\mathrm{V} 6=1\}$ & 0.409953 & 0.940217 & 1.526045 \\
\hline 6 & $\{\mathrm{~V} 8=1, \mathrm{~V} 10=1\}$ & $\{\mathrm{V} 6=1\}$ & 0.443128 & 0.939698 & 1.525203 \\
\hline 7 & $\{\mathrm{~V} 3=1, \mathrm{~V} 8=1, \mathrm{~V} 9=1\}$ & $\{\mathrm{V} 6=1\}$ & 0.400474 & 0.938889 & 1.523889 \\
\hline 8 & $\{\mathrm{~V} 8=1, \mathrm{~V} 12=1\}$ & $\{\mathrm{V} 6=1\}$ & 0.417062 & 0.93617 & 1.519476 \\
\hline 9 & $\{\mathrm{~V} 3=1, \mathrm{~V} 8=1\}$ & $\{\mathrm{V} 6=1\}$ & 0.412322 & 0.935484 & 1.518362 \\
\hline 10 & $\{\mathrm{~V} 8=1, \mathrm{~V} 9=1\}$ & $\{\mathrm{V} 6=1\}$ & 0.450237 & 0.931373 & 1.511689 \\
\hline 11 & $\{\mathrm{~V} 8=1\}$ & $\{\mathrm{V} 6=1\}$ & 0.462085 & 0.924171 & 1.5 \\
\hline
\end{tabular}

Source: own work based on calculations in the R programme

The first of the presented association rules should be interpreted in the following way: around $40.5 \%$ of all patients gave the answer YES to questions 6, 8, 10 and 12 at the same time. Moreover, in the group of patients who gave the answer YES to question 6, as many as 95\% responded YES to questions 8,10 and 12 . It can also be seen that a lift of 1.54 indicates a greatly stronger positive relationship between the answer YES to question 6 and the set of answers YES to questions 8, 10 and 12, than if the case were that answering these was independent.
In the discovered rules, the antecedent most often contained an indication of the need for introducing a uniform solution as regards telemedicine $(\mathrm{V} 8=1)$. Moreover, according to the opinions of ,conscious'patients, a uniform IT system should improve the work at primary health care institutions $(\mathrm{V} 10=1)$, introducing an on-line booking system for visits should improve the productivity and comfort of doctors $(\mathrm{V} 12=1)$, an e-prescribing system can contribute to monitoring the preparation of prescribed medication bought by the patient $(\mathrm{V} 11=1)$, and an IT system should provide unambiguous identification of a patient $(\mathrm{V} 9=1)$. Additionally, they indicate Internet accessibility (V3 $=1)$, which is without doubt a factor which facilitates obtaining knowledge about a uniform information system.

The discovered rules (Tab 2.) and the network of connections between them are presented as directed graphs in Figure 2. The initial nodes of the graphs represent the single answers in the questionnaire given by the patients, which are found in the antecedents of the association rules, the nodes in the middle represent the antecedents themselves, and the final node - the single consequent.

Graph [A] in Figure 2 shows the full network of connections between all the variables and their arrangements within

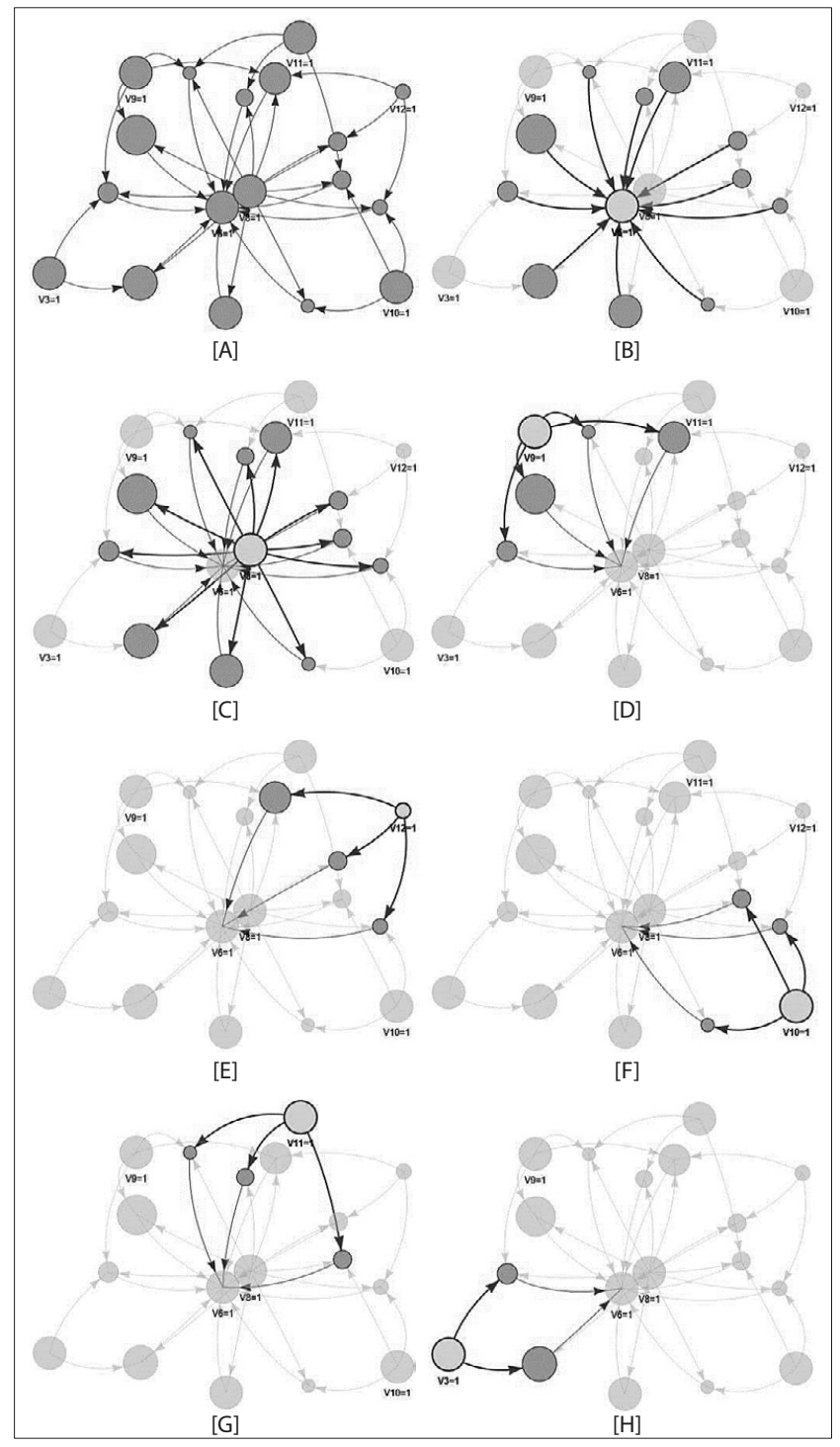

Figure 2. The connections between variables of the strongest association rules 
the discovered rules. Graph $[\mathrm{B}]$ shows the discovered rules, whereas the remaining graphs $[\mathrm{C}-\mathrm{H}]$ show the occurrence of the individual, single answers given by the patients within the rules.

Subsequently, the authors attempted to mine for analogous association rules which, in turn, would have the consequent in the form $B=\left\{V_{6}=0\right\}$, meaning it would indicate associations regarding patients with no knowledge about a uniform information system.

It turned out that with the previous minimum thresholds for support and confidence kept as they were, no such rules were found. Only when the thresholds were drastically lowered (support $\geq 0.066$ and confidence $\geq 0.7$ ), were any relationships discovered. These rules are shown in Table 3. However, despite the very high values of lift, these should be considered not credible (due to the very low support).

Table 3. Strong association rules discovered concerning the case of the lack of knowledge about a uniform information system

\begin{tabular}{llcccc}
\hline No. & antecedent $A$ & consequent $B$ & support & confidence & lift \\
\hline 1 & $\{\mathrm{~V} 11=0 . \mathrm{V} 15=0, \mathrm{~V} 17=0\}$ & $\{\mathrm{V} 6=0\}$ & 0.06872 & 0.828571 & 6.597305 \\
\hline 2 & $\{\mathrm{~V} 9=0 . \mathrm{V} 15=0, \mathrm{~V} 17=0\}$ & $\{\mathrm{V} 6=0\}$ & 0.06872 & 0.805556 & 6.414046 \\
\hline 3 & $\{\mathrm{~V} 9=0 . \mathrm{V} 15=0\}$ & $\{\mathrm{V} 6=0\}$ & 0.06872 & 0.783784 & 6.240694 \\
\hline 4 & $\{\mathrm{~V} 11=0 . \mathrm{V} 17=0\}$ & $\{\mathrm{V} 6=0\}$ & 0.06872 & 0.783784 & 6.240694 \\
\hline 5 & $\{\mathrm{~V} 7=0 . \mathrm{V} 9=0, \mathrm{~V} 17=0\}$ & $\{\mathrm{V} 6=0\}$ & 0.06872 & 0.783784 & 6.240694 \\
\hline 6 & $\{\mathrm{~V} 9=0 . \mathrm{V} 17=0\}$ & $\{\mathrm{V} 6=0\}$ & 0.06872 & 0.763158 & 6.076465 \\
\hline 7 & $\{\mathrm{~V} 11=0 . \mathrm{V} 15=0\}$ & $\{\mathrm{V} 6=0\}$ & 0.06872 & 0.763158 & 6.076465 \\
\hline 8 & $\{\mathrm{~V} 7=0 . \mathrm{V} 9=0\}$ & $\{\mathrm{V} 6=0\}$ & 0.06872 & 0.725 & 5.772642 \\
\hline 9 & $\{\mathrm{~V} 11=0\}$ & $\{\mathrm{V} 6=0\}$ & 0.07109 & 0.714286 & 5.687332 \\
\hline 10 & $\{\mathrm{~V} 9=0\}$ & $\{\mathrm{V} 6=0\}$ & 0.06872 & 0.707317 & 5.631845 \\
\hline
\end{tabular}

Source: own work based on calculations in the R programme

Exceptionally strong rules indicating negative answers were found in a very small group of people. Among the patients who do not see the need for introducing a uniform information system in health care, the respondents stated that an on-line booking of visits would not let the patient visit a GP without the inconvenient waiting outside the GPs office $(\mathrm{V} 15=0)$, introducing an e-prescribing system would not contribute to monitoring the preparation of prescribed medication bought by the patient $(\mathrm{V} 11=0)$, electronic medical documentation would not allow a decrease in erroneously issued prescriptions $(\mathrm{V} 17=0)$, and an IT system should not provide unambiguous identification of a patient $(\mathrm{V} 9=0)$. Information on the lack of knowledge about e-Health $(\mathrm{V} 7=0)$ did occur in this group. Due to very low credibility, the authors did not present the obtained results in the same scope as before for rules leading to $\mathrm{V} 6=1$.

\section{DISCUSSION}

Owing to the fact that the purpose of association analysis is to identify the relations between groups of products or services, this analysis can be useful in human resource management [17] (e.g. provision of medical services at a high level) and in offering a specific basket of services [17] (e.g. systemic solutions helpful in treatment process and improvement in communication in the relations between: patient - health care institution - doctor; patient - doctor, with the application of e-Health tools).
Proper management of health care institutions has a notable influence on the population's health. Due to the differences in policy, financing and management in such institutions, it is impossible to indicate one model of patients' basket of needs. Exploration of the association rules can help understand behaviour and preferences of patients. Kaura M. and Kang S. point to the need to implement the association analysis also in other spheres [18], including the area of e-Health tools.

Studies estimating the impact of the implementation of electronic medical documentation (EMD) and the attitudes of patients and medical personnel are conducted on many problem-related levels. Evaluating the consequences of EMD implementation, medical experts point to numerous advantages. Some results demonstrate that one-fourth of the administrative personnel of health care institutions received feedback from patients or their relatives concerning mistakes in documentation. Obviously, this makes it possible to avoid a number of medical errors. Furthermore, a vast majority of health care employees expect that more patients will have basic knowledge of their health in the future. Every fifth thinks that patients acquired better knowledge of their diagnosis and treatment [19].

Available literature points to the general benefits resulting from the introduction of e-Health. The system solutions as regards e-Health and the use of information and communication technology in health care can improve the equality in access to the health services and their quality [20]. Moreover, the use of e-Health can effectively help in meeting the needs of the patients by using tools and solutions which, among others, are made up of medical information networks, medical data gathering systems for patients of health care centres, medical web-sites, and telemedicine services [21]. E-Health is changing the conventions of the manner in which patients consult their health service providers [22].

The EMD services are especially advanced in the Scandinavian countries. Hence, it possible to carry out in-depth analyses concerning benefits derived from the implementation of these solutions there. In one such study, the respondents were asked why they were using EMD. In response, they pointed to the empowerment of a patient, greater involvement in medical treatment, and higher safety of this process. In view of the generally positive attitude to EMD, this solution seems to cater for numerous needs of patients regarding access to knowledge of their own treatment process [23]. Further research among these countries also led to interesting conclusions. A study examined patients' experiences connected with using the national e-Health service and identified its advantages and disadvantages. Much valuable information was obtained on the functioning of EMD and the quality of data contained therein. This information can be used effectively to upgrade the e-Health service on a regular basis [24].

The electronic documentation system in Norway is already well-developed and is regarded by patients as very useful. The greatest benefits are noticed by patients with chronic diseases. Information available to them via the EMD is described as useful, effective, helpful, easy, practical and safe. Furthermore, the respondents mention higher empowerment, easier communication with health care employees and better safety. However, the authors point out that it is necessary to evaluate the data exchange process on a regular basis [25]. 
The possible risks are also stated; for instance, the fact that incomplete knowledge about using e-Health instruments by the patients as well as the directors of the medical institutions can lead to inefficient and unsafe usage in the described area. Furthermore, system changes in the field of health compel a change in the attitude toward using e-Health solutions when planning medical services directed at patients. Discussions at the levels of the Ministry of Health, of the experts in the field of e-Health, the service providers and the medical service recipients, are all testimony to this [26, 27].

In this context, the authors would like to stress that getting to know the expectations and the preferences of patients is essential in the relations between all the users of the system. When the medical institutions offer their health services, it is important that tools for a numerical analysis of data are developed that will aid the diagnosing of a phenomenon under study [28]. E-Health as a young sector of knowledge has not yet received such basic tools. Its quick and dynamic development requires the use of tools and methods from other fields of knowledge and transplanting those in an educated way onto new grounds [29]. The most natural, and perhaps the simplest rule for choosing the tools to transplant, is the presence of analogies between the analysed problems [30].

A number of empirical studies have investigated the issue of advantages and barriers to EMD implementation. A review identified 176 studies of which 17 were randomized controlled trials, cohort studies or group studies. Patients reported higher satisfaction with access to information via online services compared to standard provision of services, better self-service, improved communication and involvement in interactions with a doctor. Better safety was associated by patients with an opportunity to discover errors in medical treatment and wider access to preventive services. EMD implementation is frequently connected with a need to extend the working time of a medical professional. On the other hand, no infringements on privacy and data safety were reported. Most of the analysed studies revealed that these services contribute to patients' health safety [31].

Comparison of opinions on EMD between people involved in this process and those who have not worked with data in this formula yet, demonstrates that people experienced in working with EMD are more prone to view positively selected areas of this innovation than people with no experience of EMD. Examining these two groups separately, the researchers obtained more positive opinions on the majority of the studied areas, no matter how EMD was used. Furthermore, significant problems were identified in connection with the research based on EMD evaluation questionnaires, in particular concerning the structure of the tool and quality of the planned studies [32].

The vast majority of the studies conducted in this field so far have focused on identification of individual qualities influencing the evaluation and possible benefits from the process. However, there may be gaps in the knowledge on determinants of EMD implementation at the macrosystem level, such as health care standards and financing, because few studies have dealt with these aspects to-date [33]. Dissatisfaction of service providers with the EMD application system and difficulties with implementation of EMD technology in caring for patients can adversely affect a patient's attitude. Thus, during the EMD implementation process we should remember to maintain good communication with patients and to comply with the requirements related to documentation [34].

Research into the available literature has inclined the authors to use affinity analysis in the field of e-Health, as there was a substantive lack in this field of research. There are some papers concerning the use of affinity analysis in related fields - genetics, biotechnology, and molecular analysis. As an example, the authors would like to point to papers [35] and [36] as those most related to the field of e-Health. In the work of Milewska AJ and Milewski R, the array of possibilities given by affinity analysis was only partly used $[35,36]$. That is because it was not used for discovering rules, but to assess rules previously determined (with other tools) using affinity analysis terminology; whereas in the research of Sugawara S, $\mathrm{Wu} \mathrm{T}$ and Yamanishi $\mathrm{K}$, affinity analysis was used according to its primary assumptions, but used only as an in-between tool to allow for the generalisation of another model [36].

In the case of health care institutions which are enterprises and health care institutions which are not enterprises, trust is one of the key factors influencing the effectiveness of tasks fulfilled by them. We can talk about an association between trust in quality of services and client's satisfaction [37]; hus, it seems that association analysis can facilitate an individual approach to the patient.

\section{CONCLUSIONS}

1. The IT solutions that are presently used in the field of e-Health result in the gathering of huge amounts of data (not always in an intentional and ordered way). The information contained within that data may be useful to all participants of the e-Health system (people, institutions, care centres, the state, or service market regulators) in order to, i.a. (in a broad sense) optimise the planning and continually improve the quality of services.

2. There is potential in using affinity analysis within e-Health. The example of affinity analysis described in this study led to the discovery of interesting and important (from the point of view of a medical facility) regularities regarding the knowledge and expectations of patients regarding e-Health.

3. Analogous analyses can be used in many types of research concerning the broadly understood preferences and expectations of patients, which can lead to benefits for the patients as well as the health care institutions themselves. This presents a chance to improve the quality of medical services provided, and through that to create a desirable relationship between all the parties and elements of the process of operation within primary health care.

\section{REFERENCES}

1. Wernhart A, Gahbauer S, Haluza D. eHealth and telemedicine: Practices and beliefs among healthcare professionals and medical students at a medical university. PLoS One. 2019; 14(2): 1-13. doi: 10.1371/journal. pone. 0213067

2. World Health Organization. Global diffusion of eHealth: making universal health coverage achievable. Report of the third global survey on eHealth. Geneva: World Health Organization; 2016. Licence: CC BY-NC-SA 3.0 IGO

3. Cruz-Cunha MM, Miranda IM, Martinho R, Rijo R. Encyclopedia of E-Health and Telemedicine. Med Infor Sci Ref. (IGI GLOBAL), 2016: 988-989. 
4. Kawiak-Jawor E, Pacian A, Piątkowska A, Kawiak-Zioło A, Kaczoruk M, Kaczor-Szkodny P. Application of Selected Telemedical Solutions in Dentistry. Europ J Med Technol. 2017; 4(17): 13-18.

5. Detyna B, Detyna J. Jakość usług medycznych. Ocena statystyczna. Podstawy metodyczne. Warszawa: Difin; 2011.

6. World Health Organization. Atlas of eHealth country profiles: the use of eHealth in support of universal health coverage: based on the findings of the third global survey on eHealth 2015. WHO Global Observatory for eHealth. 2016; 9-11.

7. European Comission, Communication from the Commission to the Europeanparliament, the council, the european economic and social committee and the committee of the regions on enabling the digital transformation of health and care in the Digital Single Market; empowering citizens and building a healthier socjety. 2018; 233: 1-13

8. Ossebaard HC, Van Gemert-Pijnen L. eHealth and quality in health care: implementation time. Int J Qual Health Care. 2016; 28(3): 415-419. doi: 10.1093/intqhe/mzw032

9. Bauer G. Delivering Value-Based Care With E-Health Services. J Healt Manag. 2018; 63(4): 251-260. doi: 10.1097/JHM-D-18-00077

10. Dash, S, Shakyawar SK, Sharma M, Kaushik S. Big data in healthcare: management, analysis and future prospects. J Big Data. 2019; 6(54): 3-25. doi: https://doi.org/10.1186/s40537..

11. Raghupathi W, Raghupathi V. Big data analytics in healthcare: promise and potential. Health Inf Sci Syst. 2014; 2(3): 1-10. doi: 10.1186/20472501-2-3

12. Granja C, Janssen W, Johansen MA. Factors Determining the Success and Failure of eHealth Interventions: Systematic Review of the Literature. J Med Internet Res. 2018; 20(5): 10235. doi: 10.2196/10235

13. Girardi D, Küng J, Kleiser R, Sonnberger M, Csillag D, Trenkler J, Holzinger A. Interactive knowledge discovery with the doctor-inthe-loop: a practical example of cerebral aneurysms research. Brain Informatics. 2016; 3: 133-143.

14. Hastie T, Tibshirani R, Friedman J. The Elements of Statistical Learning: Data Mining, Inference, and Prediction. Second Edition. New York Springer-Verlag; 2017

15. Larose DT, Larose ChD. Discovering Knowledge in Data: An Introduction to Data Mining, Second Edition. John Wiley \& Sons. 2014. doi: 10.1002/9781118874059

16. Hahsler M, ChelluboinaS. Visualizing Association Rules: Introduction to theR-extension PackagearulesViz. Comp Sci. 2011: 1-26.

17. Aguinis H, Forcum LE, Joo H. Using Market Basket Analysis in Management Research. JOM. 2013; 39 (7): 1799-1824.

18. Kaura M, Shivani Kanga S. Market Basket Analysis: Identify the changing trends of market data using association rule mining. Procedia Comput Sci. 2016; 85: 78-85.

19. Johansen MA, Kummervold PE, Sørensen T, Zanaboni P. Health professionals' experience with patients accessing their electronic health records: Results from an online survey. Stud Health Technol Inform. 2019; 264: 504-508. doi: 10.3233/SHTI190273

20. Murray E, May C, Mair F. Development and formative evaluation of the e-Health Implementation Toolkit (e-HIT). BMC Med Inform Decis Mak. 2010; 18 (10): 61. doi: https://doi.org/10.1186/1472-6947-10-61

21. Furtak M, Książek P, Warchoł-Sławińska E, Drop B, Włoch K, Kulbaka E. Rozwój rynku ochrony zdrowia - prognozy przyszłości. Zdr Publ. 2011; 121(1): 76-80.
22. Car J, Tan WS, Huang Z, Sloot P, Franklin BD. eHealth in the future of medications management: personalisation, monitoring and adherence. BMC Med. 2017; 15: 73. doi: https://doi.org/10.1186/s12916-017-0838-0 23. Moll J, Rexhepi H, Cajander Å, Grünloh C, Huvila I, Hägglund M, et al. Patients' experiences of accessing their electronic health records: National patient survey in Sweden. J Med Internet Res. 2018; 20(11): 278. doi: 10.2196/jmir.9492

24. Bärkås A, Scandurra I, Hägglund M. Analysis of Voluntary User Feedback of the Swedish National PAEHR Service. Stud Health Technol Inform. 2019; 264: 1126-1130. doi: 10.3233/SHTI190401

25. Zanaboni P, Kummervold PE, Sørensen T, Johansen MA. Patient Use and Experience With Online Access to Electronic Health Records in Norway: Results From an Online Survey. J Med Internet Res. 2020; 22(2): 16144. doi: 10.2196/16144

26. OSOZ. Raport „E-zdrowie: korzyści, wyzwania, strategia informatyzacji” https://www.csioz.gov.pl/aktua..

27. Maciejewski M, Surtel W, Wójcik W, Masiak J, Dzida G, Horoch A. Telemedical systems for home monitoring of patients with chronic conditions in rural environment. Ann Agric Environ Med. 2014; 21(1): 167-173.

28. Bujok J, Gierek R, Olszanowski R, Skrzypek M. Uwarunkowania rozwoju telemedycyny w Polsce - raport. Warszawa: Krajowa Izba Gospodarcza; 2015.

29. World Health Organisation. Guideline: Recommendations on digital interventions for health system strengthening. Geneva: World Health Organization. 2019; Licence: CC BY-NC-SA 3.0 IGO.

30. World Health Organisation. From innovation to implementation ehealth in the WHO European Region. World Health Organization; 2016.

31. Mold F, de Lusignan S, Sheikh A, et al. Patients' online access to their electronic health records and linked online services: a systematic review in primary care. Br J Gen Pract. 2015; 65(632): e141-e151. doi: 10.3399/bjgp15X683941

32. Bassi J, Lau F, Lesperance M. Perceived impact of electronic medical records in physician office practices: a review of survey-based research. Interact J Med Res. 2012; 1(2): e3. Published 2012 Jul 28. doi: 10.2196/ ijmr.2113

33. van Mens HJT, Duijm RD, Nienhuis R, de Keizer NF, Cornet R. Determinants and outcomes of patient access to medical records: Systematic review of systematic reviews. Int J Med Inform. 2019; 129: 226-233. doi: 10.1016/j.ijmedinf.2019.05.014

34. Meyerhoefer CD, Sherer SA, Deily ME, et al. Provider and patient satisfaction with the integration of ambulatory and hospital EHR systems. J Am Med Inform Assoc. 2018; 25(8): 1054-1063. doi: 10.1093/ jamia/ocy048

35. Milewska AJ, Milewski R. Analiza miejsca zamieszkania pacjentek kliniki ginekologii z wykorzystaniem analizy korespondencji, analizy koszykowej oraz metod klasycznych. Statystyka w badaniach biomedycznych. Kraków: StatSoft; 2014.

36. Sugawara S, Wu T, Yamanishi K. A basket two-part model to analyze medical expenditure on interdependent multiple sectors. Stat Methods Med Res. 2018; 27(5): 1585-1600. doi: 10.1177/0962280216665642

37. Błoński K. Relacja między jakością życia, zaufaniem do władz oraz satysfakcją z usług JST - w świetle wyników badania. Handel Wewnętrzny, 2017; 4(369): 19-30. 